\title{
Neighborhood-level and individual-level correlates of cannabis use among young persons living with HIV/AIDS
}

\author{
Douglas Bruce $^{1}$, Shoshana Y. Kahana ${ }^{2}$, Jose A. Bauermeister ${ }^{3}$, Sharon L. Nichols ${ }^{4}$, Lisa B. \\ Hightow-Weidman ${ }^{5}$, Justin E. Heinze ${ }^{3}$, Jaclyn Shea ${ }^{1}$, M. Isabel Fernández ${ }^{6}$, and the ATN
}

${ }^{1}$ Department of Health Sciences, DePaul University, Chicago, Illinois ${ }^{2}$ National Institutes on Drug Abuse, Bethesda, Maryland ${ }^{3}$ Department of Health Behavior and Health Education, School of Public Health, University of Michigan, Ann Arbor, Michigan ${ }^{4}$ Department of Neurosciences, UC San Diego School of Medicine, San Diego, California ${ }^{5}$ Division of Infectious Diseases, Gillings School of Global Public Health, University of North Carolina, Chapel Hill, North Carolina ${ }^{6}$ College of Osteopathic Medicine, Nova Southeastern University, Davie, Florida

\section{Abstract}

Introduction-In addition to individual characteristics, there may be a wide range of environmental or neighborhood stressors that contribute to elevated cannabis use in groups of youth living with HIV/AIDS (YLHIV); however, the effects of social disorganization on cannabis use in YLHIV to date have not been studied.

Methods-We examined the effects of individual-level and neighborhood-level factors by developing hierarchical generalized linear models estimating odds of current cannabis use (any use during the past 3 months) and daily cannabis use among a sample of YLHIV (N=1921) currently receiving medical care.

Results-The final model for daily cannabis use in the past 3 months included significant positive effects associated with hostility (O.R. $=1.08$, 95\% C.I.: 1.05, 1.11), being older (O.R.= $1.12,95 \%$ C.I.: $1.05,1.20)$, being a bisexual male (O.R. $=1.72,95 \%$ C.I.: $1.10,2.70)$, and residing in a community with a murder rate in the highest quartile (O.R.=1.91, 95\% C.I.: 1.27, 2.87), second highest quartile (O.R. $=1.62$, 95\% C.I.: 1.06, 2.46), or third highest quartile (O.R.=1.52, 95\% C.I.: $1.01,2.30)$.

Discussion-This paper advances our knowledge of the multilevel factors associated with elevated cannabis use among groups of YLHIV and furthers our understanding of social and structural determinants of health in this population. Future research into cannabis use among YLHIV should consider, not only cannabis use within the context of the adjustment of living with

\footnotetext{
(c) 2015 Published by Elsevier Ltd.

Corresponding Author: Douglas Bruce, PhD, MSW, Assistant Professor, Department of Health Sciences, DePaul University, 1110 W. Belden, Suite 411, Chicago, IL 60615, 773.325.4322, Dbruce1@ depaul.edu.

Publisher's Disclaimer: This is a PDF file of an unedited manuscript that has been accepted for publication. As a service to our customers we are providing this early version of the manuscript. The manuscript will undergo copyediting, typesetting, and review of the resulting proof before it is published in its final citable form. Please note that during the production process errors may be discovered which could affect the content, and all legal disclaimers that apply to the journal pertain.
} 
HIV/AIDS, but also the stressors that characterize the environments in which groups of YLHIV live.

\section{Keywords}

youth; cannabis (marijuana); social disorganization; neighborhood; bisexual; HIV/AIDS

\section{INTRODUCTION}

Public views on the use of marijuana or cannabis in the United States and internationally are undergoing currently a profound shift that coincides with emerging evidence of its use in the treatment of selected health conditions (Tramer et al., 2001; Watson et al., 2000), including HIV/AIDS (Abrams et al., 2003; Woolridge et al., 2005). "Medical marijuana" (including cannabinoids such as tetrahydrocannabinol (THC), cannabidiol (CBD), and their derivatives) is increasingly the focus of legislation in states in the U.S., and is already legal in Canada and several European countries. Decriminalization and legalization of recreational use of cannabis in selected jurisdictions has occurred recently, both domestically and internationally. Within this changing public sphere and clinical environment, it is important to understand the multiple influences on cannabis use among young persons living with HIV/AIDS (YLHIV). We adapted Bonfenbrenner's (1979) ecologic model to examine potential individual-level and neighborhood-level factors associated with cannabis use in this population within an ecologic framework.

\subsection{Cannabis and HIV/AIDS}

There are consistent findings that cannabis plays a role in symptoms management in HIV/ AIDS, especially the alleviation of pain and nausea in adult PLHIV (Abrams et al., 2007; Braitstein et al., 2001; Corless et al., 2009; Woolridge et al., 2005). Stress management and alleviation among adult PLHIV have been shown to be facilitated through cannabis use, although there may be significant overlap between "recreational" use and "medicinal" use when considering cannabis, stress and HIV/AIDS (D'Souza et al., 2013; Furler et al., 2004). Data are somewhat equivocal when considering the role of cannabis in facilitating adherence to HIV treatment through improved symptom management (Corless et al., 2009; DeJong et al., 2005). Few studies have investigated the role of cannabis use among YLHIV. Elevated marijuana use among HIV-positive young men who have sex with men (YMSM) has been associated with stress reduction, adjustment to an HIV/AIDS diagnosis, and relief from medication side effects (Bruce et al., 2013). Intervention studies among YLHIV have documented reductions in cannabis use via participant self-efficacy and social support, but cannabis use has proven more difficult to reduce than alcohol use in these interventions (Murphy et al., 2012; Naar-King et al., 2006).

\subsection{Individual-level factors}

Developmental and identity-related stressors also may contribute to differing levels of cannabis use among youth. Panel data has shown that cannabis use among populations in the U.S. spikes during late adolescence and emerging adulthood, with daily use among persons aged 18-24 estimated at 4-6\% (Johnson et al., 2013). The effects of peer norms and social networks (Bell et al., 1998; Kuntsche and Jordan, 2006), and identity development processes 
and stressors associated with emerging adulthood (Arnett, 2005) have been proposed as developmental mechanisms that may explain elevated use of cannabis during this period, with subsequent declines in use as individuals age over time (Johnson et al., 2013). In addition, stressors associated with sexual identity and sexual orientation may drive cannabis use among groups of YMSM (Bruce et al., 2014; Traube et al., 2013; Wong et al., 2010). Across studies, lesbian gay and bisexual youth have been more likely to report past month cannabis use than heterosexual youth (Marshall et al., 2009).

Associations between mental health and substance use disorders have been documented theoretically (Wills and Shiffman, 1985), epidemiologically (Armstrong and Costello, 2002; Compton et al., 2007), and neurobiologically (Brady and Sinha, 2005), and populations living with HIV/AIDS have been characterized by increased risk for psychiatric and substance use co-morbidities (Bing et al., 2001; Chandler et al., 2006; Walkup et al., 2008). High levels of stress and co-morbid mental health or substance use disorders associated with disease management have been found among adults living with HIV/AIDS (Brown and Vanable, 2008), yet the precise relationship between cannabis and different mood disorders is not well understood (Crippa et al., 2009). There is evidence of cannabis use by PLHIV to alleviate depression and anxiety (Prentiss et al., 2004). Among those newly diagnosed with HIV across all ages, cannabis use is higher among depressed patients while for adolescents living with HIV cannabis use is more likely among those experiencing anxiety (Bhatia et al., 2010; Korthuis et al., 2008). Health anxiety, in particular, has been found to be associated with elevated cannabis use among YLHIV (Murphy et al., 2001).

\subsection{Neighborhood-level factors}

Social disorganization and neighborhood disadvantage have been theorized to be related to substance use through a number of stress mechanisms, including social interactions and discrimination, decreased social resources available to individuals, the undermining of individuals' psychological resources, and increased psychological distress (Boardman et al., 2001). Multiple studies have linked neighborhood disadvantage, disorganization, or disorder to increased drug use among adults (Boardman et al., 2001; Karriker-Jaffe, 2013; Latkin et al., 2007) as well as adolescents (Furr-Holden et al., 2011; Tucker et al., 2013; Winstanley et al., 2008).

Examination of National Longitudinal Study of Adolescent Health (Add Health) panel data has shown high neighborhood unemployment to be the most consistent predictor of initiation of cannabis use, with stronger associations than individual and social network factors (Tucker et al., 2013). A significantly greater prevalence of cannabis use has been found among sexual minority youth living in neighborhoods with higher prevalence of LGBT assault hate crimes (Duncan et al., 2014). Among African American youth, perceived neighborhood violence has been shown to be significantly associated with greater cannabis use, while perceived control is correlated with less cannabis use (Lambert et al., 2004). For YLHIV, in addition to developmental, identity-related, and HIV-related stressors, as well as associated mental health issues, there may be a wide range of environmental or neighborhood stressors that contribute to elevated cannabis use in groups of YLHIV from

Drug Alcohol Depend. Author manuscript; available in PMC 2016 June 01. 
disadvantaged communities; however, the effects of social disorganization on cannabis use in YLHIV to date have not been studied.

\subsection{Aims of Current Study}

In light of the evidence that cannabis use may be associated with individual-level and neighborhood-level factors, we aimed to examine the effects of these multiple factors by developing hierarchical generalized linear models estimating odds of current cannabis use (any use in the past 3 months) and daily cannabis use among YLHIV. We hypothesized that (1) lesbian gay or bisexual sexual orientation, higher levels of mental health symptomology, and recent HIV diagnosis and (2) greater social disorganization as indicated by higher levels of poverty, unemployment, crime, and housing vacancy would be positively associated with current and daily use.

\section{METHODS}

\subsection{Study procedures}

From December, 2009 to June, 2012, 2,225 YLHIV receiving primary care at 20 geographically diverse clinics within the Adolescent Medicine Trials Network for HIV/ AIDS Interventions (ATN) were recruited to participate in a cross-sectional survey (see Acknowledgements for the 17 metropolitan areas represented). To be eligible, youth had to be: 1) between 12 and 26 years of age (inclusive); 2) living with HIV/AIDS; 3) aware they were HIV-infected; 4) engaged in care in one of the ATN's clinical sites or affiliates; and 5) able to understand English or Spanish.

Written informed consent or assent was obtained from all participants to (1) an audiocomputer assisted self-interview (ACASI) to assess psychosocial factors, and (2) medical record abstraction to extract clinical data such as antiretroviral therapy (ART) usage and viral load (HIV RNA) assay results. Most sites did not require parental consent for participants younger than 18 , in order to protect the confidentiality of participants and their HIV status, although parental consent was obtained at sites where it was required by the local institutional review board (IRB). Participants were given a small incentive the amount determined by each IRB based on previous history of research with YLHIV at each site. The study was reviewed by community advisory boards at each site and approved by the IRBs at each site as well as those from the members of the protocol team. It is the policy of the ATN for protocol teams to write a lay summary of findings to be distributed to study participants at each site.

\subsection{Measures}

2.2.1. Cannabis Use-We used the Alcohol, Smoking and Substance Involvement Screening Test (ASSIST) (WHO ASSIST Working Group, 2002) to assess cannabis use, including (1) ever using cannabis during the past 3 months, and (2) frequency of use among current cannabis users during the past three months. Current use was defined as any use during the past 3 months. Frequency of current use was assessed with a four-point scale: once or twice, monthly, weekly, daily or almost daily. To analyze daily use, we dichotomized the frequency variable into "daily (or almost daily)"/"less than daily."

Drug Alcohol Depend. Author manuscript; available in PMC 2016 June 01. 
2.2.2. Mental Health Symptoms-Mental health symptoms were assessed with the Brief Symptom Inventory (BSI; DeRogatis and Spencer, 1982) which yields nine primary symptom scales, and a global severity index (GSI). For the purposes of descriptive and multivariate analyses, mean scores were calculated for the anxiety, depression, hostility subscales, and GSI. Subscale reliability in the current study was high: anxiety $(a=.86)$, depression $(a=.88)$, and hostility ( $a=.84)$.

2.2.3. HIV-related Measures-Participants who reported being on ART and had a current regimen identified during medical chart review were classified as "on ART." Participants who had been diagnosed with HIV/AIDS within the past 12 months were classified as "newly diagnosed." Participants' plasma HIV RNA obtained within the last six months and type of assay were abstracted from medical records, and a dichotomous variable was created to designate virologic detectability (non-suppressed) vs. non-detectability (suppressed).

2.2.4. Neighborhood-level Data-Geographically dependent neighborhood-level variables were collected from a number of existing sources and appended to the data collected at clinical sites using participant residential zip code as a geographical identifier. We included the following variables in our analysis: percent of persons unemployed (from 2010 U.S. Census), percent of persons below federal poverty rate (from 2010 U.S. Census), murder rate index in 2010 (from Esri Crime database), assault rate index in 2010 (from Esri Crime database), percent of housing units that are vacant (from 2011 American Community Survey). To align census-derived data with participant residential zip codes we used the 2010 Zip Code Tabulation Area (ZCTA), a spatial unit developed by the U.S. Census Bureau to be comparable to zip codes (http://www.census/gov/geo/reference/zctas.html). Consistent with prior studies (Kim et al., 2010; Steptoe and Feldman, 2001), neighborhoodlevel variables were modeled as quartiles, with the lowest quartile serving as the reference category in all analyses.

\subsection{Data Analysis}

Descriptive analyses were conducted using PASW (SPSS), version 18.0. We computed frequencies, means and other measures of central tendency of use of cannabis, mental health, HIV-related, demographic, and neighborhood-level factors (see Tables 1 and 2). Quartile distributions of unemployment, poverty, and vacant housing percentages, and murder and assault rates were converted to four-point categorical ordinal variables.

We constructed a correlation matrix to assess bivariate relationships and examine possible collinearity between variables of interest. Hierarchical generalized linear models (HGLM) were then developed using HLM7® software (SSI, Inc.) to examine individual- and neighborhood-level factors associated with (1) any cannabis use during the past 3 months and (2) daily cannabis use during the past 3 months. In accordance with standard practices in the development of hierarchical linear models (Raudenbush and Bryk, 2002), we first ran unconditional models to examine the variance of the two outcome variables. Each unconditional model assumed a Bernoulli distribution that specified:

Drug Alcohol Depend. Author manuscript; available in PMC 2016 June 01. 


$$
\begin{array}{cc}
\text { Level 1 } & \operatorname{Prob}(\mathrm{Y}=1 / \beta)=\mathrm{P} \\
& \log [\mathrm{P} /(1-\mathrm{P})]=\beta_{0} \\
\text { Level } 2 & \beta_{0}=\gamma_{00}+\mu_{0}
\end{array}
$$

\begin{abstract}
After the initial variance was determined in the unconditional models, individual-level variables of interest were entered as fixed effects at Level 1. Variables were first entered as fixed effects for two reasons. First, due to our use of secondary data, we did not assume that we were modeling all variables that could possibly explain the nature of cannabis use in this population, which is often seen as criteria for random effects models (Allison, 2009).

Second, we would include a random variance term in each equation, and based on the results of the model iterations determine whether there was a sufficient change in variance across models that would merit including random effects in future model iterations.

Level 1 variables were entered in the following ordered blocks: (1) personal demographics (race/ethnicity, sexual orientation, age), (2) mental health variables (depression, anxiety, hostility, GSI), (3) HIV-related markers (new diagnosis in past 12 months, being on antiretroviral therapy, having an undetectable viral load). Variables that demonstrated statistical significance $(p<.05)$ were retained in successive model iterations until all variables remaining in the model were statistically significant at Level 1 . We then modeled quartiles of neighborhood-level factors (murder, poverty, and unemployment quartiles) as dummy variables and entered them as fixed effects at Level 2 (with the lowest quartile serving as referent). Neighborhood-level factors that demonstrated statistical significance at Level 2 were retained in successive model iterations until all variables remaining in the model were statistically significant.
\end{abstract}

\title{
3. RESULTS
}

\subsection{Participant Characteristics}

Participants who did not report zip codes $(n=219)$ were removed from the data set prior to analysis. We deleted participants cases from the Puerto Rico ATN site $(\mathrm{n}=25)$ as neighborhood-level variables were not available for ZCTAs in Puerto Rico, leaving a final dataset $(\mathrm{N}=1921)$ for analyses. We assessed missing data with variables to be entered into our models using chi-square and t-tests and determined that the missing data was missing completely at random (MCAR). Fifty percent of participants $(n=954)$ had used cannabis in the past 3 months, and 20\% $(n=381)$ used cannabis daily. Only 3\% $(n=68)$ had used alcohol daily during the same period, and similar low proportions had used other drugs at any time during the past 3 months (amphetamines, 11\%; cocaine, 7\%; hallucinogens, 2\%). Participant characteristics of the total sample, as well as those who used any cannabis during the past 3 months, and those who used cannabis daily appear in Table 1.

\subsection{Neighborhood-level Characteristics}

There were 784 ZCTAs represented among the 1921 participants remaining after initial data cleaning. The number of participant observations within the ZCTAs ranged from 1 to 22 . The means and quartile distribution of the community characteristics appear in Table 2.

Drug Alcohol Depend. Author manuscript; available in PMC 2016 June 01. 


\subsection{Bivariate Analyses}

We examined bivariate correlations among the variables of interest with the two outcomes (any cannabis use during past 3 months, daily cannabis use during past 3 months) to assess collinearity. Results of correlational analysis appear in Table 3. Since there was a high level of collinearity (1) among the BSI-subscales and the GSI, and (2) between neighborhoodlevel murder rate quartiles and assault rate quartiles, we chose to enter these variables one at a time in their respective blocks in the hierarchical models below. Due to our interest in differentiating possible effects of a range of mental health symptoms on cannabis use, we retained the BSI-subscales and the GSI as possible predictors to be entered into the models. We selected the murder rate quartiles as the crime variable of interest to be entered at Level 2 , and did not include assault rates, as the murder rate quartiles demonstrated significant bivariate correlations with both of the two cannabis use outcomes. Similarly, we did not enter housing vacancy percentage quartiles in the HGLM models due to the lack of significance with the cannabis outcomes in the bivariate analysis.

\subsection{Hierarchical Generalized Linear Models}

Cases with missing data were deleted when entering the datasets into HLM, resulting in final samples analyzing associations with current use/no current use $(n=1840)$ and associations with daily use/less than daily use among current users ( $n=916)$. Analyses of the unconditional model for any current cannabis use during the past 3 months demonstrated significant variance at Level $2(p<.05)$, and there was also significant variance at Level 2 in the daily cannabis use unconditional model ( $p<.001)$, suggesting rates of both current and daily marijuana usage differed between ZCTAs.

3.4.1. Current Cannabis Use-When demographic variables were entered into the current cannabis use model, significant associations at Level 1 were found with identifying as gay male, bisexual male, or bisexual female, as well as with older age. Hostility demonstrated the only significant association among the mental health variables, and when the mental health variables were entered at Level 1, being transgender no longer retained statistical significance. ART use produced a significant negative association with current cannabis use, but the other HIV-related markers entered into the model did not. None of the neighborhood-level variables entered at Level 2 demonstrated statistical significance. The final model for current cannabis use in the pasts 3 months included significant positive fixed effects associated with increased hostility (O.R. $=1.10,95 \%$ C.I.: $1.08,1.13)$, older age $($ O.R. $=1.13$, 95\% C.I.: 1.08, 1.17), identifying as a gay male (O.R. $=1.63$, 95\% C.I.: 1.30, 2.04), identifying as a bisexual male (O.R. $=2.43,95 \%$ C.I.: $1.72,3.42)$, and identifying as a bisexual female (O.R. $=2.34,95 \%$ C.I.: $1.41,3.90)$, with significant negative fixed effects associated with ART use (O.R. $=0.67,95 \%$ C.I.: 0.55, 0.81). Results including fixed effect coefficients, odds ratios, and confidence intervals from the population-average model using robust standard errors are depicted in Table 4.

3.4.2. Daily Cannabis Use-As in the current use model, bisexual males and older participants reported higher odds of being daily cannabis users; however, no other demographic variables were significantly associated with daily use. Similar to the current use model, hostility was significantly associated with daily cannabis use. None of the HIV-

Drug Alcohol Depend. Author manuscript; available in PMC 2016 June 01. 
related variables were statistically significant when entered at Level 1 . When neighborhoodlevel quartiles were entered at Level 2 , the highest poverty quartile and highest unemployment quartile demonstrated significant associations with daily use, as did the top three murder quartiles, in separate models. When multiple neighborhood-level variables were entered at Level 2 simultaneously, none retained their significance, which may be a function of their significant correlations with one another. We chose to retain the model with murder quartiles entered at Level 2, as this model demonstrated the best model fit compared to the poverty or unemployment models based on comparison of log likelihood statistics. The final model for daily cannabis use included significant positive effects associated with hostility (O.R. $=1.08$, 95\% C.I.: 1.05, 1.11), being older (O.R.=1.12, 95\% C.I.: 1.05, 1.20), being a bisexual male (O.R. $=1.72,95 \%$ C.I.: $1.10,2.70)$, and residing in a community with a murder rate in the highest quartile (O.R. $=1.91,95 \%$ C.I.: $1.27,2.87)$, second highest quartile (O.R. $=1.62$, 95\% C.I.: 1.06, 2.46), or third highest quartile (O.R. $=1.52$, 95\% C.I.: $1.01,2.30)$. Results from the population-average model using robust standard errors are depicted in Table 4.

\section{DISCUSSION}

This paper presents the first analysis that simultaneously estimates individual-level and neighborhood-level factors of daily cannabis use among YLHIV. Our findings help to disentangle a range of factors that are associated with elevated cannabis use among this population, identifying important factors to consider regarding the role of cannabis in the lives of YLHIV. Current and daily cannabis use appear to be highly prevalent in this population, with proportions greatly exceeding those of daily alcohol use or other current drug use in the sample, and prevalence of daily use was over three times that of similarly aged youth in national population-based samples (Johnson et al., 2013). None of the neighborhood-level variables entered at level 2 of the "current use" HLM models demonstrated statistical significance, suggesting that current or more casual cannabis use is significantly associated with individual level factors and not community level factors among this population.

Participants living in communities with the first, second, and third highest quartiles of murder rates were significantly more likely to use cannabis daily, with YLHIV living in communities in the highest quartile almost twice as likely to use daily as those living in communities in the lowest quartile. We found significant associations with daily use and living in communities in the highest poverty quartile and the highest unemployment quartile, although these associations were not significant when all neighborhood-level variable quartiles were entered simultaneously. These relationships between living in socially disorganized and disadvantaged neighborhoods and elevated cannabis use confirm previous findings in the literature, and point to significant stressors in the lives of groups of YLHIV above and beyond stress associated with living with HIV/AIDS.

Hostility as measured by the BSI was significantly associated with both current and daily cannabis use in this paper, while anxiety and depression were not. In HIV clinical practice the hostility symptom dimension may not be captured by standard screening tools or clinical inquiry. Current clinical practice could be improved with the use of appropriate tools and 
procedures to screen and diagnose not only the most common mental health disorders, such as depression and anxiety but also to capture experiences such as irritability, outbursts of temper and frequent arguments. Previous research has identified initiation of cannabis use during adolescence as an outcome of hostility and aggression experienced during childhood (Fite et al., 2008; Hampson et al., 2010) and early adolescence (Ohannessian and Hesselbrock, 2009). There is mixed evidence that links antisocial behavior as an outcome of elevated cannabis use in prospective studies, but most effects are substantially reduced when adjusted for confounding psychosocial factors (Macleod et al., 2004).

Although multiple LGBT sexual orientation identities (gay male, bisexual male, bisexual female) were significantly associated with current cannabis use compared to heterosexual youth, only being a bisexual male significantly increased the likelihood of daily use. These results align with previous research showing health disparities among bisexual male youth compared to gay-identified male youth (Agronick et al., 2004; Gwadz et al., 2006), and such findings underscore the importance of future research into disparities within LGBT populations. Emerging research suggests that bisexual males may have fewer social support resources, and experience more isolation, stigma and identity-related stressors than gayidentified males (Dodge and Sandfort, 2007; Friedman et al., 2014), but the unique stressors that place HIV-positive bisexual male youth at risk for elevated cannabis use are not well understood and merit further investigation.

Current and daily cannabis use in our study was not significantly associated with a recent HIV diagnosis suggesting that cannabis may not serve specifically as a coping response to the stress of an HIV diagnosis, and we found no significant associations between either level of cannabis use and having an undetectable viral load. Being on ART produced a significant negative association with current cannabis use compared to non-users, but there was no significant difference between current and daily users and being on ART. Future research may help explain differences in providers' perception of casual cannabis use and prescription of ART, although confounding factors may be at work that were not available for this analysis (e.g., assessment of patient readiness for ART, providers' adherence to ART guidelines).

Given the high prevalence of daily cannabis use in this sample, and the use of cannabis among other groups of persons living with HIV/AIDS, it will become increasingly important to study the long-term effects of cannabis use among PLHIV. While cannabis use has been shown not to have an adverse effect on viral load or CD4 among persons living with HIV/ AIDS (Abrams et al., 2003), long-term effects of chronic cannabis use have been shown to include increased risk in adults for pulmonary diseases (Wu et al., 1988), and cognitive dysfunction (Solowij et al., 2002). A significant concern regarding cannabis use in adolescents and young adults in general is its impact on the central nervous system, particularly in light of ongoing brain development (Lenroot and Giedd, 2006; Lebel and Beaulieu, 2011). The implications for YLHIV may be even greater. Existing studies demonstrate significant neurocognitive impairments among YLHIV (Nichols, 2013); however, the role of cannabis use in these impairments is not well understood. Studies of the impact of this widely used substance on the neurology and immunology of YLHIV are needed. 
Our study is not without limitations. The cross-sectional data in this study limits our ability to infer causality from our multilevel model, and our assessment of community level factors was restricted in a number of ways. We did not know how long each participant had been living in their current neighborhood, and were unable to assess how effects of social disorganization might be differentiated by length of exposure. Further, our analyses are limited by the use of zip-code level data for neighborhood-level factors, as zip codes may not always be congruent with neighborhoods. The generalizability of our findings to all YLHIV may be limited due to participants in this study being recruited as part of their participation in ATN trials, and thus represent YLHIV in care at selected adolescent medicine clinics. We relied on self-reported data (except for HIV-related measures abstracted from participant charts), but we believe that the use of an ACASI to gather data may have lessened the inclination of participants to underreport levels of cannabis use and mental health symptomology. Measures of social support, characteristics of substance use within social networks, and physiological and self-reported stress measures, may help further explain from an ecologic perspective potential relationships between communitylevel, interpersonal and individual-level factors and elevated cannabis use in this population.

This paper advances our knowledge of the multilevel factors associated with elevated cannabis use among groups of YLHIV and furthers our understanding of social and structural determinants of health behaviors in this population. Future research into cannabis use among YLHIV should consider, not only cannabis use within the context of the adjustment of living with HIV/AIDS, but also the stressors that characterize the environments in which groups of YLHIV live. The prevalence of daily use in this sample is of concern, given emergent research on effects of elevated cannabis use on the neurological development of young persons. The connections between violence, trauma, stress, sexual identity development, and cannabis use that emerge from this study merit further investigation to more fully understand how this substance may be used by populations of atrisk youth within rapidly changing legal and medicinal landscapes.

\section{References}

Abrams DI, Hilton JF, Leiser RJ, Shade SB, Elbeik TA, Aweeka FT, Benowitz NL, Bredt BM, Kosel B, Aber JA, Deeks SG, Mitchell TF, Mulligan K, Bacchetti P, McCune JM, Schambelan M. Shortterm effects of cannabinoids in patients with HIV-1 infection: a randomized placebo-controlled clinical trial. Ann Int Med. 2003; 139:258-266. [PubMed: 12965981]

Abrams DI, Jay CA, Shade SB, Vizoso H, Reda H, Press S, Kelly ME, Rowbotham MC, Peterson KL. Cannabis in painful HIV-associated sensory neuropathy: a randomized placebo-controlled trial. Neurology. 2007; 68:515-521. [PubMed: 17296917]

Agronick G, O’Donnell L, Stueve A, San Doval A, Duran R, Vargo A. Sexual behaviors and risks among bisexually-identified and gay-identified young Latino men. AIDS Behav. 2004; 8:185-197. [PubMed: 15187480]

Allison, P. Fixed Effects Regression Models. Sage; Thousand Oaks, CA: 2009.

Armstrong TE, Costello EJ. Community studies on adolescent substance use, abuse, or dependence and psychiatric morbidity. J Consult Clin Pscyhol. 2002; 70:1224-1239.

Arnett JJ. The developmental context of substance use in emerging adulthood. J Drug Issues. 2005; 35:235-253.

Bell R, Pavis S, Cunningham-Burley S, Amos A. Young men's use of cannabis: exploring changes in meaning and context over time. Drugs Educ Prev Policy. 1988; 5:141-155.

Drug Alcohol Depend. Author manuscript; available in PMC 2016 June 01. 
Bhatia R, Hartman C, Kallen MA, Graham J, Girodano TP. Persons newly diagnosed with HIV infection are at high risk for depression and poor linkage to care. AIDS Behav. 2011; 15:11611170. [PubMed: 20711651]

Bing EG, Burnam MA, Longshore D, Fleishman JA, Sherbourne CD, London AS, Turner BJ, Eggan F, Beckman R, Vitiello B, Morton SC, Orlando M, Bozzette SA, Ortiz-Barron L, Shapiro M. Psychiatric disorders and drug use among human immunodeficiency virus-infected adults in the United States. Arch Gen Psychiatry. 2001; 58:721-728. [PubMed: 11483137]

Boardman JD, Finch BK, Ellison CG, Williams DR, Jackson JS. Neighborhood disadvantage, stress, and drug use among adults. J Health Soc Behav. 2001; 42:151-165. [PubMed: 11467250]

Brady KT, Sinha R. Co-occurring mental and substance use disorders: the neurobiological effects of chronic stress. Am J Psychiatry. 2005; 162:1483-1493. [PubMed: 16055769]

Braitstein P, Kendall T, Chan K, Wood E, Montaner JSG, O'Shaughnessy MV, Hogg RS. Mary-jane and her patients: sociodemographic and clinical characteristics of HIV-positive individuals using medical marijuana and antiretroviral agents. AIDS. 2001; 15:532-33. [PubMed: 11242154]

Bronfenbrenner, U. The Ecology Of Human Development. Harvard University; Cambridge, MA: 1979.

Brown JL, Vanable PA. Cognitive-behavioral stress management interventions for persons living with HIV: a review and critique of the literature. Ann Behav Med. 2008; 35:26-40. [PubMed: 18347902]

Bruce D, Harper GW, Fernández MI. the Adolescent Medicine Trials Network for HIV AIDS Interventions. Heavy marijuana use among gay and bisexual male emerging adults living with HIV/AIDS. J HIV/AIDS Soc Serv. 2013; 12:66-88.

Bruce D, Stall R, Fata A, Campbell R. Modeling effects of minority stress on homelessness and health disparities among young men who have sex with men. J Urban Health. 2014; 91:568-580. [PubMed: 24807702]

Buu A, DiPiazza C, Wang J, Puttler LI, Fitzgerald HE, Zucker RA. Parent, family, and neighborhood effects on the development of child substance use and other psychopathology from preschool to the start of adulthood. J Stud Alcohol Drugs. 2009; 70:489-498. [PubMed: 19515288]

Chandler G, Himelhoch S, Moore RD. Substance abuse and psychiatric disorders in HIV-positive patients. Drugs. 2006; 66:769-789. [PubMed: 16706551]

Compton WM, Thomas YF, Stinson FW, Grant BF. Prevalence, correlates, disability and comorbidity of DSM-IV drug abuse and dependence in the United States. Arch Gen Psychiatry. 2007; 64:566576. [PubMed: 17485608]

Corless IB, Lindgren T, Holzemer W, Robinson L, Moezzi S, Kirksey K, Coleman C, Tsai Y, Eller LS, Hamilton MJ, Sefcik EF, Canaval GE, Mendez MR, Kemppainen JK, Bunch EH, Nicholas PK, Nokes KM, Dole P, Reynolds N. Marijuana effectiveness as an HIV self-care strategy. Clin Nurs Res. 2009; 18:172-193. [PubMed: 19377043]

Crippa JA, Zuardi QW, Martin-Santos R, Bhattacharyya S, Atakan Z, McGuire P, Fusar-Poli P. Cannabis and anxiety: a critical review of the evidence. Hum Psychopharmacol. 2009; 24:515523. [PubMed: 19693792]

DeJong BC, Prentiss D, McFarland W, Machekano R, Israelski DM. Marijuana use and its association with adherence to antiretroviral therapy among HIV-infected persons with moderate to severe nausea. J AIDS. 2005; 38:43-46.

Derogatis, L.; Spencer, M. The Brief Symptom Inventory (BSI): Administration, Scoring, And Procedures Manual-1. Johns Hopkins University School of Medicine, Clinical Psychometrics Research Unit; Baltimore, MD: 1982.

Dodge, B.; Sandfort, T. A review of mental health research on bisexual individuals when compared to homosexual and heterosexual individuals. In: Firestein, B.; Green, B., editors. Becoming Visible: Counseling Bisexuals across the Lifespan. Columbia University. Press; New York: 2007. p. 28-51.

D’Souza G, Matson P, Grady CD, Nahvi W, Merenstein D, Weber K, Greenblatt R, Burian P, Wilson TE. Medicinal and recreational marijuana use among HIV-infected women in the Women's Interagency HIV Cohort (WIHS), 1994-2010. J AIDS. 2013; 61:618-626. 
Duncan DT, Hatzenbuehler ML, Johnson RM. Neighborhood-level LGBT hate crimes and current illicit drug use among sexual minority youth. Drug Alcohol Depend. 2014; 135:65-70. [PubMed: 24326203]

Fite PJ, Colder CR, Lochman JE, Wells KC. The relation between childhood proactive and reactive aggression and substance use initiation. J Abnorm Child Psychol. 2008; 36:261-271. [PubMed: 17823863]

Fogarty A, Rawstorne P, Prestage G, Crawford J, Grierson J, Kippax S. Marijuana as therapy for people living with HIV/AIDS: Social and health aspects. AIDS Care. 2007; 19:295-301. [PubMed: 17364413]

Friedman MR, Dodge B, Shick V, Herbenick D, Hubach R, Bowling J, Goncalves G, Krier S, Reece M. From bias to bisexual health disparities: attitudes toward bisexual men and women in the U.S. LGBT Health. 2014; 1:309-318. [PubMed: 25568885]

Furler MD, Einarson TR, Millson M, Walmsley S, Bendayan R. Medicinal and recreational marijuana use by patients infected with HIV. AIDS Pat Care STDs. 2004; 18:215-227.

Furr-Holden CDM, Lee MH, Milan AJ, Johnson RM, Lee K, Ialongo NS. The growth of neighborhood disorder and marijuana use among urban adolescents: A case for policy and environmental interventions. J Stud Alcohol Drugs. 2011; 72:371-379. [PubMed: 21513673]

Gwadz MV, Clatts MC, Yi H, Leonard NR, Goldsamt L, Lankenau S. Resilience among young men who have sex with men in New York City. Sex Res Soc Policy. 2006; 3:13-21.

Hampson SE, Tildesley E, Andrew JA, Luycks K, Mroczek DK. The relation of change in hostility and sociability during childhood to substance use in mid adolescence. J Res Pers. 2010; 44:103114. [PubMed: 20401178]

Johnson, LD.; O’Malley, PM.; Backman, JG.; Schulenberg, JE. Monitoring The Future National Survey Results On Drug Use, 1975-2012: Vol. 2, College Students And Adults Ages 19-50. Institute for Social Research, the University of Michigan; Ann Arbor, MI: 2013.

Kahana SY, Fernández MI, Wilson PA, Bauermeister JA, Lee S, Wilson CM, Hightow-Weidman LB. Rates and correlates of antiretroviral therapy use and virologic suppression among perinatally and behaviorally infected HIV-positive youth linked to care in the United States. J AIDS. 2015; 68:169-177.

Karriker-Jaffe KJ. Neighborhood socioeconomic status and substance use by U.S. adults. Drug Alcohol Depend. 2013; 133:212-221. [PubMed: 23726978]

Kim D, Diez Roux AV, Kiege CI, Kawachi I, Liu K. Do neighborhood socioeconomic deprivation and low social cohesion predict coronary calcification? The CARDIA Study. Am J Epidemiol. 2010; 172:288-298. [PubMed: 20610467]

Korthuis PT, Zephyrin LC, Fleishman JA, Saha S, Josephs JS, McGrath MM, Hellinger J, Gebo KA. Health-related quality of life in HIV-infected patients: the role of substance use. AIDS Pat Care STDs. 2008; 22:859-867.

Kuntsche E, Jordan MG. Adolescent alcohol and cannabis use in relation to peer and school factors: Results of multilevel analyses. Drug Alcohol Depend. 2006; 84:167-174. [PubMed: 16542799]

Lambert SF, Brown TL, Phillips CM, Ialongo NS. The relationship between perceptions of neighborhood characteristics and substance use among urban African American adolescents. Am J Community Psychol. 2004; 34:205-218. [PubMed: 15663207]

Latkin CA, Curry AD, Hua W, Davey MA. Direct and indirect associations of neighborhood disorder with drug use and high-risk sexual partners. Am J Prev Med. 2007; 32(Suppl):S234-S241. [PubMed: 17543716]

Lebel C, Beaulieu C. Longitudinal development of human brain wiring continues from childhood into adulthood. J Neurosci. 2011; 31:10937-10947. [PubMed: 21795544]

Lenroot RK, Giedd JN. Brain development in children and adolescents: insights from anatomical magnetic resonance imaging. Neurosci Biobehav Res. 2006; 30:718-729.

Macleod J, Oakes R, Copello A, Crome I, Egger M, Hickman M, Oppenkowskik T, Stokes-Lampard H, Smith GD. Pschological and social sequelae of cannabis and other illicit drug use by young people: a systematic review of longitudinal, general populations studies. Lancet. 2004; 363:15791588. [PubMed: 15145631]

Drug Alcohol Depend. Author manuscript; available in PMC 2016 June 01. 
Marshall MP, Friedman MS, Stall R, King KM, Miles J, Gold MA, Bukstein OG, Morse JQ. Sexual orientation and adolescent substance use: a meta-analysis and methodological review. Addiction. 2009; 103:546-556.

Murphy DA, Durako SJ, Mosicki AB, Vermund SH, Ma Y, Schwarz DF, Muenz LR. No change in health risk behaviors over time among HIV infected adolescents in care: role of psychological distress. J Adolesc Health. 2001; 29:57-63. [PubMed: 11530304]

Murphy DA, Chen X, Naar-King S, Parsons JT. the Adolescent Medicine Trials Network for HIV AIDS Interventions. Alcohol and marijuana use outcomes in the Healthy Choices Motivational Interviewing intervention for HIV-positive youth. AIDS Pat Care STDs. 2012; 26:95-100.

Naar-King S, Wright K, Parsons JT, Frey M, Templin T, Lam P, Murphy D. Healthy Choices: Motivational enhancement therapy for health risk behaviors in HIV-positive youth. AIDS Educ Prev. 2006; 18:1-11. [PubMed: 16539572]

Nichols SL, Bethel J, Garvie PA, Patton DE, Thornton S, Kapogiannis BG, Ren W, Major-Wilson H, Puga A, Woods SP. Neurocognitive functioning in antiretroviral therapy-naive youth with behaviorally acquired human immunodeficiency virus. J Adolesc Health. 2013; 53:763-771. [PubMed: 23972941]

Ohannessian CM, Hesselbrock VM. A finer examination of the role that negative affect plays in the relationship between paternal alcoholism and the onset of alcohol and marijuana use. J Stud Alcohol Drugs. 2009; 70:400-408. [PubMed: 19371491]

Prentiss D, Power R, Balmas G, Tzuang G, Israelski DM. Patterns of marijuana use among patients with HIV/AIDS followed in a public health care setting. J AIDS. 2004; 35:38-45.

Raudenbush, SW.; Bryk, AS. Hierarchical Linear Models: Applications and Data Analysis Methods. 2. Sage; Newbury Park, CA: 2002.

Rhodes J, Jason LA. A social stress model of substance abuse. J Consult Clin Psychol. 1990; 58:395401. [PubMed: 2212175]

Roberts AL, Austin SB, Corliss HL, Vandermorris AK, Koenen KC. Pervasive trauma exposure among U.S. sexual orientation adults and risk of posttraumatic stress disorder. Am J Public Health. 2010; 100:2433-2441. [PubMed: 20395586]

Solowij N, Stephens RS, Roffman RA, Babor T, Kadden R, Miller M, Christiansen K, McRee B, Vendetti J. for the Marijuana Treatment Project Group. Cognitive functioning of long-term heavy cannabis users seeking treatment. JAMA. 2002; 287:1123-1131. [PubMed: 11879109]

Steptoe A, Feldman PJ. Neighborhood problems as sources of chronic stress: Development of a measure of neighborhood problems, and associations with socioeconomic status and health. Ann Behav Med. 2001; 23:177-185. [PubMed: 11495218]

Tramer MR, Carroll D, Campbell FA, Reynolds DJM, Moore RA, McQuay HJ. Cannabinoids for control of chemotherapy induced nausea and vomiting: quantitative systematic review. BMJ. 2001; 323:16-21. [PubMed: 11440936]

Traube DE, Schrager SM, Holloway IW, Weiss G, Kipke MD. Environmental risk, social cognition, and drug use among young men who have sex with men: longitudinal effects of minority status on health processes and outcomes. Drug Alcohol Depend. 2013; 127:1-7. [PubMed: 22749680]

Tucker JS, Pollard MS, de la Haye K, Kennedy DP, Green HD. Neighborhood characteristics and the initiation of marijuana use and binge drinking. Drug Alcohol Depend. 2013; 128:83-89. [PubMed: 22938829]

Walkup J, Blank MB, Gonzalez JS, Safren S, Schwartz R, Brown L, Wilson I, Knowlton A, Lombard F, Grossman C, Lyda K, Schumacher JE. The impact of mental health and substance use factors on HIV prevention and treatment. J AIDS. 2008; 47 (Supp 1):S15-S19.

Watson SJ, Benson JA, Joy JE. Marijuana and medicine: assessing the science base: a summary of the 1999 Institute of Medicine report. Arch Gen Psychiatry. 2000; 57:547-552. [PubMed: 10839332]

WHO ASSIST Working Group. The Alcohol, Smoking and Substance Involvement Screening Test (ASSIST): development, reliability and feasibility. Addiction. 2001; 97:1183-94.

Wills, TA.; Shiffman, S. Coping and substance use: a conceptual framework. In: Shiffman, S.; Wills, TA., editors. Coping and Substance Use. Academic Press; Orlando, FL: 1985. p. 3-24.

Winstanley EL, Steinwachs DM, Ensminger ME, Latkin CA, Stitzer ML, Olsen Y. The association of self-reported neighborhood disorganization and social capital with adolescent alcohol and drug 
use, dependence, and access to treatment. Drug Alcohol Depend. 2008; 92:173-182. [PubMed: 17913396]

Wong CF, Weiss G, Ayala G, Kipke M. Harassment, discrimination, violence and illicit drug use among young men who have sex with men. AIDS Educ Prev. 2010; 22:286-298. [PubMed: 20707690]

Woolridge E, Barton S, Samuel J, Osorio J, Dougherty A, Holdcroft A. Cannabis use in HIV for pain and other medical symptoms. J Pain Symptom Manag. 2005; 29:358-367.

Wu TC, Tashkin DP, Djahed B, Rose JE. Pulmonary hazards of smoking marijuana as compared with tobacco. New Engl J Med. 1988; 318:347-351. [PubMed: 3340105] 
- Hierarchical generalized linear models estimated odds of daily cannabis use.

- Hostility, being older, and being a bisexual male increased the odds of daily use.

- Residing in a community with a murder rate increased odds of daily use.

- Multiple stressors influence elevated cannabis use among youth living with HIV (YLHIV). 


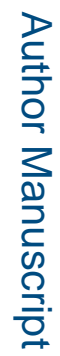

要

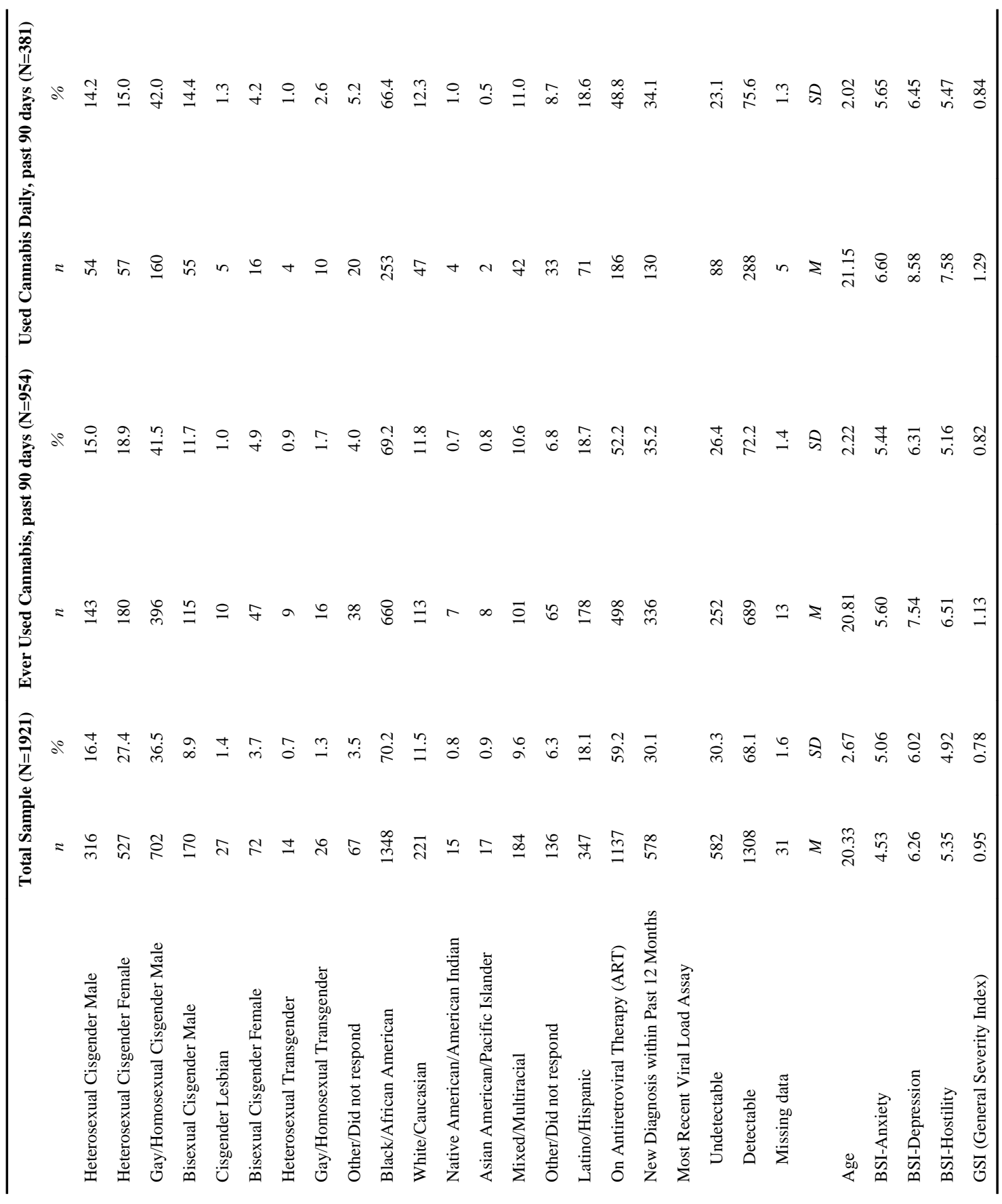

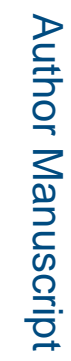

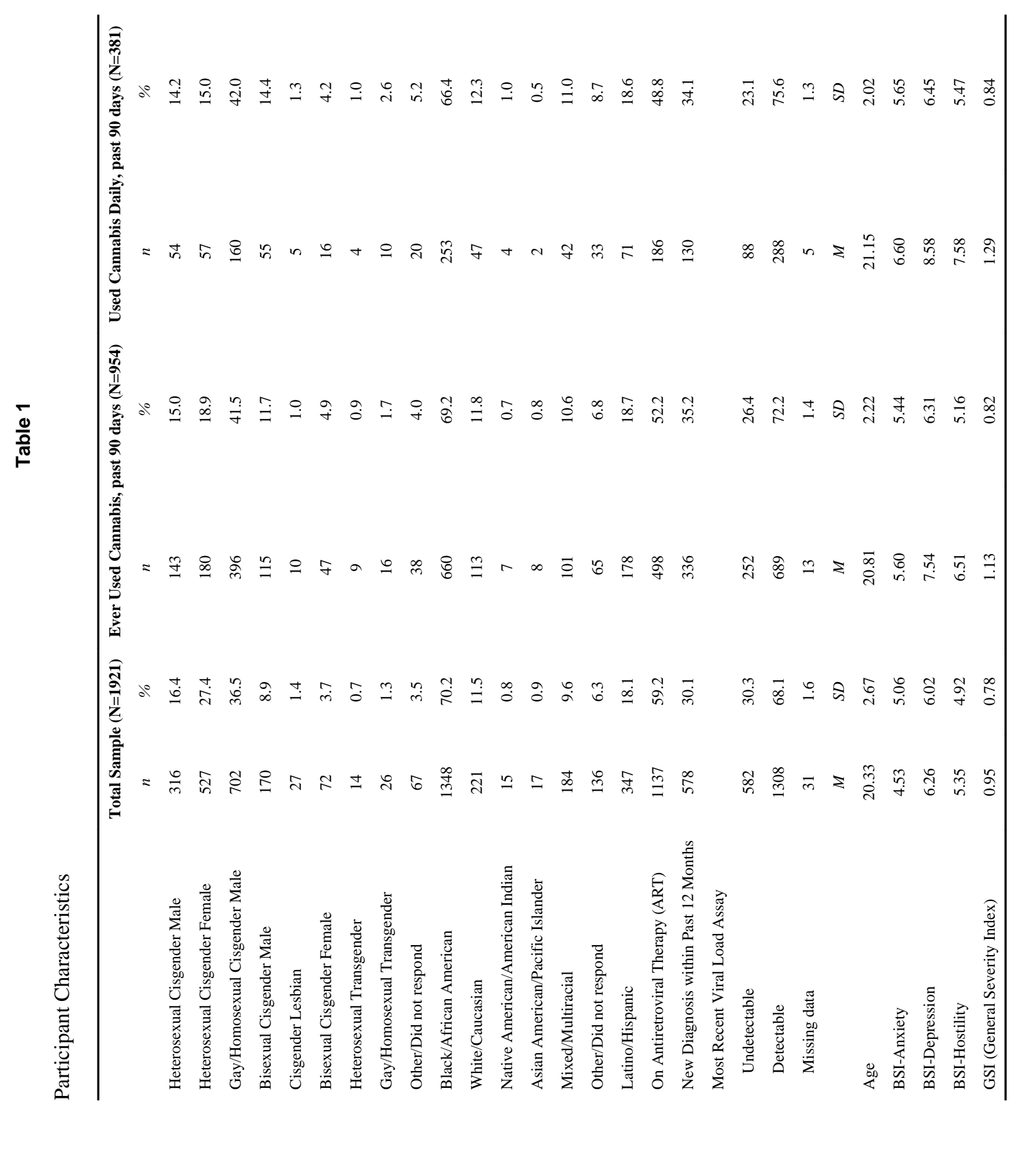

Drug Alcohol Depend. Author manuscript; available in PMC 2016 June 01. 


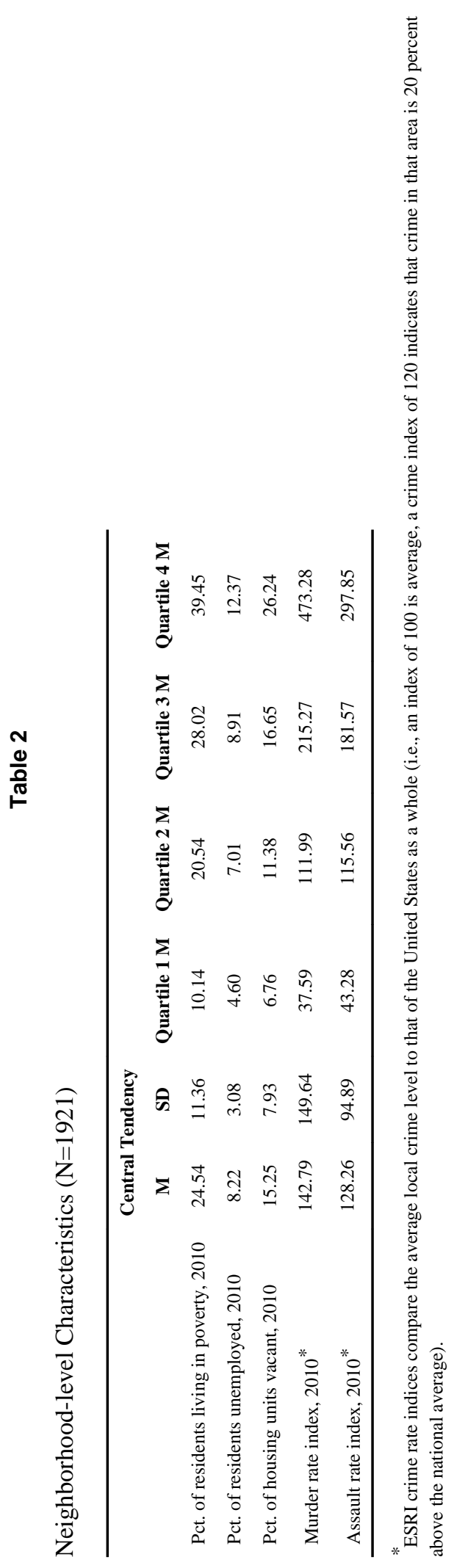




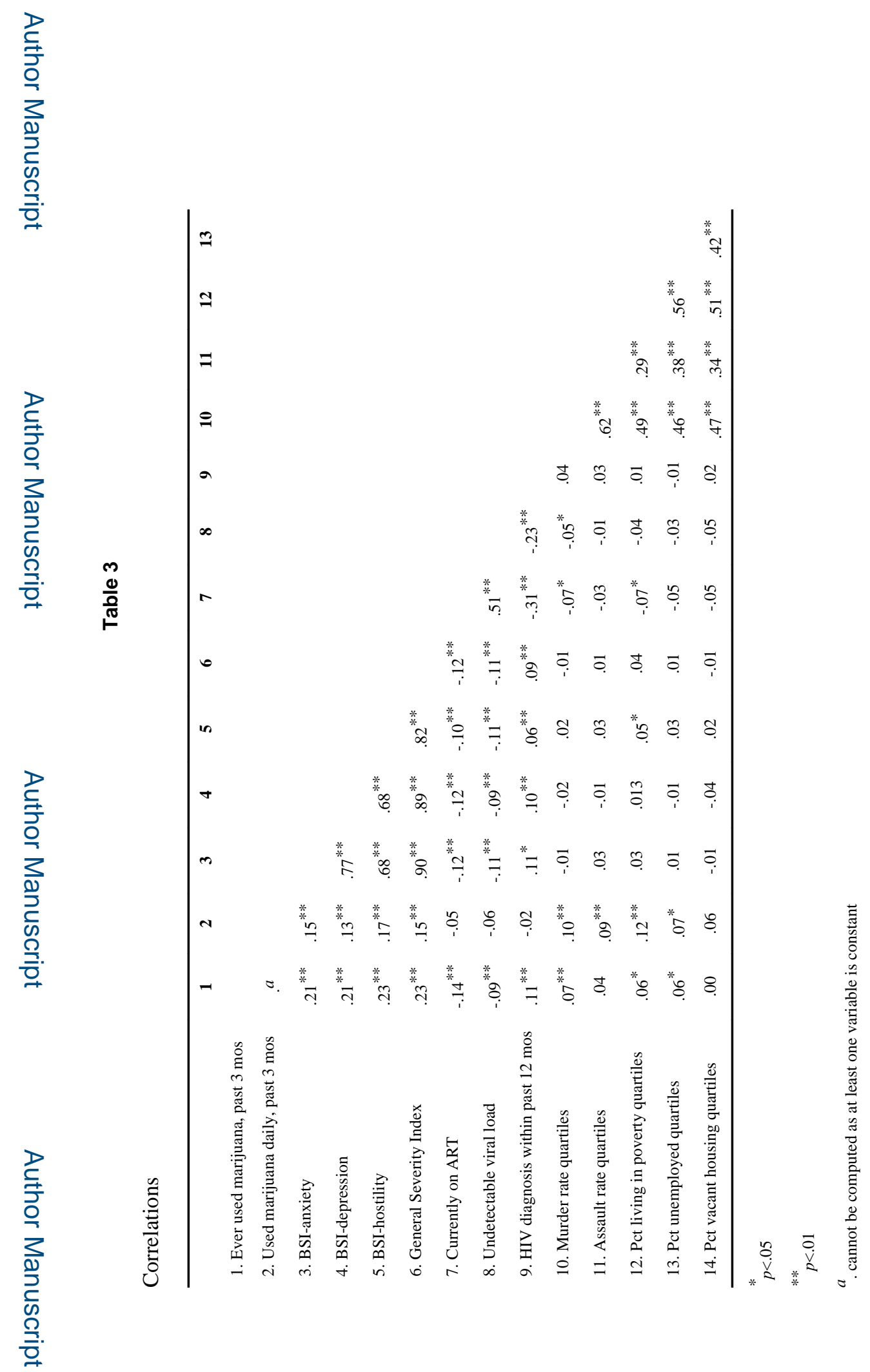

Drug Alcohol Depend. Author manuscript; available in PMC 2016 June 01. 


\section{Table 4}

Final estimates of fixed effects of current use of cannabis and daily use of cannabis (Population-average model with robust standard errors)

\begin{tabular}{|c|c|c|c|c|}
\hline & \multicolumn{2}{|c|}{ Any current use of cannabis $(\mathbf{N}=\mathbf{1 8 4 0})$} & \multicolumn{2}{|c|}{ Daily Use of cannabis $(\mathrm{N}=916)$} \\
\hline & Coefficient & O.R. $(95 \%$ CI $)$ & Coefficient & O.R. $(95 \% \mathrm{CI})$ \\
\hline \multicolumn{5}{|l|}{ For Intercept $1, B_{0}$} \\
\hline Intercept $2, \gamma_{00}$ & $-3.08^{* * *}$ & $0.05(0.02,0.10)$ & $-3.87^{* * *}$ & $0.02(.01, .09)$ \\
\hline Murder, $2^{\text {nd }}$ quartile, $\gamma_{01}$ & $\S$ & $\S$ & $0.48^{*}$ & $1.62(1.06,2.46)$ \\
\hline Murder, $3^{\text {rd }}$ quartile, $\gamma_{02}$ & $\S$ & $\S$ & $0.42^{*}$ & $1.52(1.01,2.30)$ \\
\hline Murder, $4^{\text {th }}$ quartile, $\gamma_{03}$ & $\S$ & $\S$ & $0.65^{* *}$ & $1.91(1.27,2.87)$ \\
\hline For Gay Male slope, $B_{1}$ Intercept $2, \gamma_{10}$ & $0.49^{* * *}$ & $1.63(1.30,2.04)$ & 0.12 & $1.12(.83,1.53)$ \\
\hline For Lesbian slope, $B_{2}$ Intercept $2, \gamma_{20}$ & -0.40 & $0.67(.23,1.91)$ & 0.69 & $1.99(.48,8.16)$ \\
\hline For Bisexual Male slope, $B_{3}$ Intercept $2, \gamma_{30}$ & $0.89^{* * *}$ & $2.43(1.72,3.42)$ & $0.54^{*}$ & $1.72(1.10,2.70)$ \\
\hline For Bisexual Female slope, $B_{4}$ Intercept $2, \gamma_{40}$ & $0.85^{* *}$ & $2.34(1.41,3.90)$ & -0.18 & $0.83(.44,1.57)$ \\
\hline For Transgender slope, $B_{5}$ Intercept $2, \gamma_{50}$ & 0.66 & $1.94(.93,3.99)$ & 0.69 & $1.99(.79,5.03)$ \\
\hline For Age slope, $B_{6}$ Intercept $2, \gamma_{60}$ & $0.12^{* * *}$ & $1.13(1.08,1.17)$ & $0.12^{* * *}$ & $1.12(1.05,1.20)$ \\
\hline For BSI-Hostility slope, $B_{7}$ Intercept $2, \gamma_{70}$ & $0.99^{* * *}$ & $1.10(1.08,1.13)$ & $0.079^{* * *}$ & $1.08(1.05,1.11)$ \\
\hline For ART slope, $B_{8}$ Intercept $2, \gamma_{80}$ & $-0.40^{* * *}$ & $0.67(0.55,0.81)$ & $\S$ & $\S$ \\
\hline \multicolumn{5}{|l|}{$*_{p<.05}$} \\
\hline \multicolumn{5}{|l|}{$* * * 0.01$} \\
\hline$* * * p^{*}<.001$ & & & & \\
\hline
\end{tabular}

